Portland State University

PDXScholar

\title{
Evidence from Urban Roads without Bicycle Lanes on the Impact of Bicycle Traffic on Passenger Car Travel Speeds
}

\author{
Jaclyn S. Schaefer \\ Portland State University \\ Miguel A. Figliozzi \\ Portland State University, figliozzi@pdx.edu \\ Avinash Unnikrishnan \\ Portland State University, uavinash@pdx.edu
}

Follow this and additional works at: https://pdxscholar.library.pdx.edu/cengin_fac

Part of the Transportation Engineering Commons

Let us know how access to this document benefits you.

\section{Citation Details}

Jaclyn S. Schaefer, Miguel A. Figliozzi, Avinash Unnikrishnan, (2020). Evidence from Urban Roads without Bicycle Lanes on the Impact of Bicycle Traffic on Passenger Car Travel Speeds, 1-12. http://doi.org/ $10.1177 / 0361198120920880$

This Post-Print is brought to you for free and open access. It has been accepted for inclusion in Civil and Environmental Engineering Faculty Publications and Presentations by an authorized administrator of PDXScholar. Please contact us if we can make this document more accessible: pdxscholar@pdx.edu. 


\section{Evidence from Urban Roads without Bicycle Lanes on the Impact of Bicycle Traffic on Passenger Car Travel Speeds}

3

\section{Jaclyn S. Schaefer}

Department of Civil and Environmental Engineering

Portland State University, Portland, OR, 97201

Email: jsschae@pdx.edu

Miguel A. Figliozzi (corresponding author)

Department of Civil and Environmental Engineering

Portland State University, Portland, OR, 97201

Email: figliozzi@pdx.edu

\section{Avinash Unnikrishnan}

Department of Civil and Environmental Engineering

Portland State University, Portland, OR 97201

Email: uavinash@pdx.edu

\section{Please cite as:}

Schaefer, J.S., Figliozzi, M.A. and Unnikrishnan, A., 2020. Evidence from Urban Roads without Bicycle Lanes on the Impact of Bicycle Traffic on Passenger Car Travel Speeds. Transportation Research Record, Vol. 2674(7) 87-98 


\section{ABSTRACT}

2 A concern raised by some motorists regarding the presence of bicycles on urban roads without bicycle 3 lanes, discussed in part of the traffic literature, is that cyclists will slow down motorized vehicles and 4 therefore create congestion. This research answers this question: do bicycles reduce passenger car travel 5 speeds on urban roads without bicycle lanes? To answer this question, a detailed comparative analysis of 6 passenger car (class two vehicles) travel speeds on lower volume urban roads without bicycles lanes is 7 presented. Speed distributions, the mean, and the $50^{\text {th }}$ and $85^{\text {th }}$ percentile speeds for two scenarios were 8 examined: (i) a passenger car that was preceded by a bicycle and (ii) a passenger car that was preceded by 9 another passenger car. Peak hour traffic and 24-hour traffic speeds were analyzed using $t$-tests and 10 confidence intervals. Although a few statistically significant differences between scenarios (i) and (ii) 11 were found, the actual speed differences were generally on the order of one mile per hour or less. Hence, 12 differences in class two (motorized passenger) vehicle speeds with and without cyclists were found to be 13 negligible from a practical perspective.

Keywords: Shared, local, arterial roads, vehicle-bicycle interaction, speed, distributions. 


\section{INTRODUCTION}

Bicycling is a vastly underutilized mode throughout most of the US, comprising just half of a percent of commuters throughout the nation.[1] Given its potential for greater flexibility in route choice and lower costs for infrastructure and operation compared to transit, there is a substantial opportunity for cities to expand bicycling as a primary transportation mode. Congestion mitigation and environmental concerns from rising urban populations have been significant factors cited by communities as they push for greener transportation policies and travel modes.

According to the Portland Bureau of Transportation, in 2017, 6.3\% of commuters traveled by bicycle.[2] The Portland Bike Plan has established a goal to increase that mode share to $25 \%$ by the year 2030.[3] With this mode shift toward bicycling, it is necessary to study the impacts these changes may have on the existing transportation network and motorized vehicles. In support of the Portland Bike Plan's goal to reach a $25 \%$ bicycle mode share, the City expects to add nearly 100 miles $(161 \mathrm{~km})$ of bikeways to the existing 385 miles (620 km), approximately 36\% of which are currently shared-use roadways.[2]

Although it is generally favored to segregate bicyclists and motor vehicles, it is infeasible and often unnecessary to create such infrastructure on every road. For example, Danish bicycle design guidelines suggest that mixed traffic conditions are acceptable for roadways with speed limits less than approximately $35 \mathrm{~km} / \mathrm{h}(22 \mathrm{mph})$ and ADT less than approximately 2500 vehicles.[4]

Shared-use roads can be an economical solution to a growing demand for bicycle facilities. However, this sharing of space presents its own challenges in the contexts of safety and mobility. Several research studies have been conducted on vehicle-bicycle interactions, many of them focused on lateral positioning and passing behavior. Of particular interest, however, is the effect of bicycle traffic on motorized traffic speed, capacity, and flow.

A general concern of motorists regarding the presence of bicycles on roads without bicycle lanes is that they will impede motor vehicles due to their differing performance characteristics, which may serve to increase congestion and vehicle emissions - two consequences of urbanization that a larger bicycle mode share seeks to mitigate. Recent discussions based on a simulated traffic study have warned that traffic congestion and travel time delay will worsen as the bicycle mode share increases unless bicycle lanes are installed.[5-6] To the authors' knowledge, there have not been any studies to date using empirical data of passenger cars on shared roads or roads without bicycle lanes that explore the validity of this claim. This paper seeks to expand the knowledge on vehicle-bicycle interactions by studying the impact of bicycles on the travel speed of passenger cars on roadways without bicycle lanes.

\section{LITERATURE REVIEW}

Shared roads or roads without explicit bicycle lanes can constitute a considerable portion of an urban bicycle network. Danish bikeway design guidelines suggest that mixed traffic conditions are acceptable for roadways with low speed limits (less than $35 \mathrm{~km} / \mathrm{h}$ [22 mph]) and low traffic volumes (less than 2500 ADT).[4] The FHWA lays out similar guidelines, advising shared roadways are suitable in urban areas on streets with speeds of $25 \mathrm{mph}(40 \mathrm{~km} / \mathrm{h})$ or less and a maximum of 3,000 ADT.[7-8] The National Association of City Transportation Officials (NACTO) also recommends a target speed of 20-25 $\mathrm{mph}(32-40 \mathrm{~km} / \mathrm{h})$ and traffic volumes below 1,500 vehicles per day for shared streets to be appropriate for all ages and abilities.[9]

In light of the growing trend of bicycling as a transportation mode, there is a considerable need for additional research into how bicycles affect traffic operations, particularly in these mixed traffic contexts. Relatively few studies have attempted to model vehicle-bicycle interactions as they relate to travel speed or delay.

Bicycles may interact with motor vehicles in a number of ways, including their position relative to each other and their lateral movements. Conflicts can arise when bicycles and motor vehicles attempt to occupy the same space due to lane changes and merging, turning movements, or shared roadways. The differential in performance characteristics between bicycles and motor vehicles, particularly on roadways 
with significant positive grades, contributes to the potential for these conflicts as motor vehicles frequently operate at higher speeds and desire to overtake slower moving bicycles.

Jia et al. [10] describe two types of influence bicycles may impose upon motor vehicles, namely friction interference and block interference. Even when a bicyclist is riding within a dedicated bicycle lane, a motor vehicle may slow down when passing on account of safety. This is referred to as friction interference. Block interference occurs when a bicyclist occupies a portion of the motor lane, causing a trailing motor vehicle to reduce its speed. On shared roadways, it has been demonstrated that shared lane markings encourage bicyclists to ride farther from the curb in a more central position within the lane [1113] which may increase instances of block interference on shared roads.

In the absence of empirical data, simulations have been used to study vehicle-bicycle interactions. Oketch [14] designed a model using a deterministic car following rule to simulate heterogeneous traffic behavior in which multiple types of non-motorized vehicles were present along with conventional motor vehicles. Speed-flow relationships were developed, and trends in capacity and saturation flows were analyzed for a two-lane road with three meters (10 ft.) lane widths. The average desired speed was set to $80 \mathrm{~km} / \mathrm{h}$ (50 mph) with a flow of 1000 vehicles per hour to model a typical urban arterial road. Results of a simulation comprised of $25 \%$ bicycles and $75 \%$ private cars showed a $36 \%$ decrease in capacity versus a homogenous traffic stream of private cars. This decrease in capacity was attributed to a reduction in the mean free flow speed. However, it is important to note the desired motor vehicle speed and traffic flow values utilized in these simulations far exceed the bicycle design recommendations for mixed traffic roadways.

Bicycle lane provisions and bicycle volume have been found to affect the average velocities of cars in China. Researchers in Beijing collected and analyzed field data for three sections of road with designated bicycle lanes of varying width and $3.7 \mathrm{~m}$ (12 ft.) motor vehicle lanes using photography to quantify the impact bicycles exert on vehicles in mixed urban traffic. The researchers observed that as the number of bicycles increased or the width of the bicycle lane decreased, motor vehicles were increasingly affected by block interference as opposed to friction interference due to the overflow of bicycles into the motor vehicle lane, which offered insufficient space to pass. The average velocities of cars on the three road sections when no interference occurred ranged from $35.15 \mathrm{~km} / \mathrm{h}$ to $41.56 \mathrm{~km} / \mathrm{h}$ (21.84 mph to 25.82 $\mathrm{mph}$ ). Compared to conditions where no interference occurred, a $17-21 \%$ decrease in average velocity was observed when friction interference was present. Under block interference conditions, a 29-37\% decrease in average velocity was seen as compared to no interference.[10]

Bicycle lane width, motor vehicle lane width, and traffic volume - both motor vehicle and bicycle - influence lateral movements and passing behavior, which may, in turn, affect speed and travel time. Using a simulation of a two-lane urban roadway and based on a motor vehicle speed of $37.4 \mathrm{mph}$ (60 $\mathrm{km} / \mathrm{h}$ ), Gosse \& Clarens [6] found that a 10\% bicycle mode share incurred travel time delay costs when shared travel lanes were not sufficiently wide to allow heavy vehicles to pass safely. This effect was magnified on sections with a positive $4 \%$ grade. In their simulations, the researchers concluded a curb-tocurb road width of $8.6 \mathrm{~m}$ (28.2 ft.) or greater provided adequate space for larger vehicles to pass and resulted in reduced travel time delay costs with a $10 \%$ bicycle mode share.

Unlike previous (cited) studies that utilize simulations to analyze motorized traffic delays due to the presence of cyclists, this research utilizes empirical traffic speed and vehicle classification data that was collected at six different locations with different roadway geometric design and topography in Portland, Oregon.

\section{DATA COLLECTION}

The City of Portland, Oregon is well known throughout the US for its bicycling culture. There are currently 385 miles $(620 \mathrm{~km})$ of bikeways in Portland with an additional 95 miles (153 km) being installed in the next five years. Over 100 miles $(161 \mathrm{~km})$ of the existing bikeways are shared roadways.[2] In order to investigate the effect bicycles may have on passenger car travel speeds on shared-use roadways or roads without bicycle lanes, traffic speed survey data was sourced from the Portland Bureau of Transportation (PBOT). PBOT uses pneumatic tubes configured to record vehicle speed and classify 
the vehicle according to the number of axles and the axle spacing detected. PBOT uses a modified FHWA Scheme F [15] to classify vehicles with bicycles included as class one and passenger cars as class two. Pneumatic tubes are commonly used for short-term traffic counts. Although pneumatic tubes have a general tendency to undercount bicycles, Nordback et al.[16] found that the JAMAR tubes performed better than two other brands of classification counters tested and that manually computed bicycle speeds were in agreeance with those reported by the JAMAR model. The Portland Bureau of Transportation has been using JAMAR brand tube counters for many years and the crews are experienced regarding appropriate placement of the tubes to gather counts and speeds for both motorized vehicles and bicycles.

The data, collected at six different sites, was sourced from available PBOT speed data collection efforts and selected based on the availability of data within the context of roadways without bicycle lanes. Bidirectional data was available for five of the six sites, producing a total of eleven datasets. The posted speed limit at the time of collection for all sites was $25 \mathrm{mph}(40 \mathrm{~km} / \mathrm{h})$. Grades ranged from flat to greater than $4 \%$, all positive in the eastbound direction. Table 1 describes the basic geometric and traffic characteristics of each site including the percentage of class one vehicles and estimated ADT.

SE Harrison St and SE Lincoln St are classified by the City as local streets. Additionally, they are designated as neighborhood greenways - streets with low speed limits and low volumes where bicyclists are encouraged to travel. The speed limit and traffic volume on these streets can be considered within the design recommendations for mixed traffic roadways. These streets are two-way, two lanes, and parallel parking is permitted on both sides of the street, although it is minimally utilized along Harrison and moderately utilized along Lincoln. Formerly a double yellow center lane was present along SE Harrison St. However, it has been allowed to fade to a nearly imperceptible state except within roughly 40 feet (12 $\mathrm{m}$ ) of a traffic control device. Lane markings along SE Lincoln St are only present near traffic control devices. Sharrows (shared lane markings) are present along both SE Harrison St and SE Lincoln St. Bicycle lanes are absent at all locations presented in Table 1.

\section{Insert Table 1 HERE}

SE Hawthorne Blvd is classified as a district collector. It is a two-way road with one lane in each direction and a center turn lane. Parallel parking is also permitted on both sides of the road and is frequently occupied. No sharrows are present at this location.

A few of the data collection sites have additional, noteworthy characteristics. All-way stop signs are present at the intersection of SE Harrison and $30^{\text {th }}$ and the intersection of SE Harrison and $26^{\text {th }}$. The Lincoln site is situated midway between two speed humps, approximately 460 feet $(140 \mathrm{~m})$ apart. Figures 1 through 3 provide street level views of a representative site along SE Harrison, the SE Lincoln site, and the SE Hawthorne site, respectively.[17-19]

\section{Insert Figures 1, 2, and 3 HERE}

Speed distributions of class one vehicles were inspected as part of the data cleaning process. Vehicle speeds appeared to be normally distributed for all datasets. Figure 4 provides a representative example of class one speed distributions, showing those from the SE Harrison west of $30^{\text {th }}$ location. Mean class one speeds at this location were $11.2 \mathrm{mph}(18 \mathrm{~km} / \mathrm{h})$ and $11.9 \mathrm{mph}(19 \mathrm{~km} / \mathrm{h})$ for the eastbound and westbound directions, respectively.

\section{Insert Figure 4 HERE}

\section{ANALYSIS}

Motorized vehicles may be forced to reduce their speed before or during overtaking maneuvers when approaching a slower-moving bicycle from behind. Data was selected for the following two scenarios. (i) Observations of a class two vehicle (passenger car) that was preceded by a class one vehicle (bicycle) and (ii) observations of a class two vehicle (passenger car) preceded by another class two 
vehicle (passenger car) were selected for analysis from the datasets supplied. The data were selected as such to test the hypothesis that bicycles provoke reduced passenger car travel speeds on roads without bicycle lanes, either by friction or block interference.

The timestamp associated with each observation in the datasets allowed the gap time between the vehicle of interest and the preceding vehicle to be calculated. An analysis of gap time versus speed was performed to determine whether a correlation between them was present. A vehicle with a smaller gap time may be influenced by the preceding vehicle to a greater degree than one with a larger gap time. A series of plots were constructed, and linear correlation coefficients were calculated to inspect for a relationship between gap time and speed. Should one such relationship exist, we might expect to see some degree of positive correlation, particularly for vehicles following a bicycle. In traffic engineering and speed studies a gap of four to six seconds is usually used as a threshold to determine if the leading vehicle is affecting the behavior of the follower.

Comparisons of speed between the two vehicle configurations were made in several ways. First, mean speed was calculated for each configuration of class two vehicles in each dataset, and a two-sample $t$-test was performed. To further evaluate the practical implication of any difference in speed for the two configurations, $50^{\text {th }}$ and $85^{\text {th }}$ percentile speeds with $95 \%$ confidence intervals were calculated and compared.

Each dataset was first analyzed for a whole day (24-hour period) and was then analyzed for peak hour traffic separately. A potential limitation of this study is the inability of the traffic monitoring equipment (pneumatic tubes) to differentiate between motorized and non-motorized class one vehicles. This limitation was regarded as irrelevant to this study due to the negligible percentage of traffic that motorcycles typically comprise [20] and observed to be the case, too in Portland urban area roads.

\section{RESULTS \\ 24-Hour Period}

Figure 5 presents the speed-gap plots generated for the SE Harrison west of $23^{\text {rd }}$ westbound dataset and their associated r-values noted as a typical example for all sites. With r-values close to zero, it can clearly be seen that the disaggregated data are highly scattered, and no apparent relationship exists between gap time and vehicle speed for either vehicle configuration. This finding was consistent throughout all of the datasets analyzed where linear correlation coefficients were low and not significant. A subsequent analysis limited to observations with a gap time of 10 s or less presented comparable results. Figure 6 displays the speed-gap plots of the westbound SE Harrison west of $23^{\text {rd }}$ dataset when limited to a 10s gap time.

\section{Insert Figures 5 and 6 HERE}

The results of the $t$-tests can be seen in Table 2, along with the mean class one speeds for reference. The null hypothesis is defined as scenarios (i) and (ii) having equal mean speeds. The null is rejected when there is a statistically significant difference between the mean speeds. If the difference is not statistically significant, we fail to reject the null. Five of the eleven datasets show a statistically significant difference at the $p=0.05$ level, rejecting the null hypothesis.

Figure 7 displays the empirical speed distributions and mean speeds for the westbound SE Harrison east of $27^{\text {th }}$ dataset and the eastbound SE Harrison west of $23^{\text {rd }}$ dataset. These empirical distributions also provide a visual of the level of compliance to the posted speed limit. At the westbound SE Harrison east of $27^{\text {th }}$ location, the proportion of observations exceeding the posted speed limit was $24.9 \%$ and $31.48 \%$ for scenarios (i) and (ii), respectively. At the eastbound SE Harrison west of $23^{\text {rd }}$ location, $24.0 \%$ and $17.45 \%$ of observations exceeded the speed limit for scenarios (i) and (ii), respectively. 
Schaefer, Figliozzi, and Unnikrishnan

\section{Insert Table 2 HERE}

\section{Insert Figure 7 HERE}

Table 3 presents the results of the calculated 95\% confidence intervals for the $50^{\text {th }}$ percentile speeds. Only one dataset, the westbound direction at SE Harrison east of $27^{\text {th }}$, shows non-overlapping confidence intervals for the $50^{\text {th }}$ percentile speeds. Apart from this dataset, a high degree of overlap is observed. It can be observed that the intervals may differ by approximately one mile per hour $(1.6 \mathrm{~km} / \mathrm{h})$ or less for all locations where sharrows are present. A broader confidence interval is given for scenario (i) at the SE Hawthorne location, yet the confidence interval for scenario (ii) remains within these bounds.

\section{Insert Table 3 HERE}

Table 4 gives the results for the $85^{\text {th }}$ percentile speed confidence intervals. As with those of the $50^{\text {th }}$ percentile speeds, the confidence intervals for the two vehicle configurations here correspond well with each other, reinforcing the previous findings of this analysis. The SE Hawthorne east of $44^{\text {th }}$ dataset displays the greatest amount of discrepancy between the two vehicle configurations for the $85^{\text {th }}$ percentile speed confidence intervals while the westbound SE Harrison west of $30^{\text {th }}$ dataset are nearly identical. The empirical distributions and $85^{\text {th }}$ percentile speeds for these datasets are plotted in Figure 8. Notice the high percentage of observations in excess of the posted speed limit for both scenarios (i) and (ii) at the SE Hawthorne location (50.0\% and $68.88 \%$, respectively) compared to the westbound SE Harrison west of $30^{\text {th }}$ location of $19.0 \%$ for scenario (i) and $19.8 \%$ for scenario (ii).

\section{Insert Table 4 HERE}

\section{Insert Figure 8 HERE}

\section{Peak-Hour Period}

To address concerns that changes in passenger car speeds due to bicycles may only occur during peak traffic hours when the volume is highest, a separate analysis was performed. The traffic volume distribution by the time of day indicated the morning peak hours to be 7:30 am to 9:30 am and the evening peak hours to be $4: 30 \mathrm{pm}$ to $6: 30 \mathrm{pm}$. Due to an insufficient number of data points, the SE Hawthorne east of $44^{\text {th }}$ location was not evaluated for peak hours.

The speed-gap time analysis was performed again for peak hours. The resulting range of linear correlation coefficients was similar to that of the 24-hour period traffic with low and insignificant coefficients of correlation. This outcome seems to verify the absence of a relationship between gap time and vehicle speed in the data presented here.

The $t$-tests between mean speeds for peak hour traffic (Table 5) revealed only one dataset, westbound SE Harrison west of $30^{\text {th }}$, that rejected the null hypothesis with a statistically significant result $(p=0.034)$. The difference in mean speeds was calculated to be less than one mile per hour $(1.6 \mathrm{~km} / \mathrm{h})$. Interestingly, this dataset was also one of the five in which the null hypothesis was rejected when the 24hour period was analyzed.

\section{Insert Table 5 HERE}


The evaluation of the $95 \%$ confidence intervals for the $50^{\text {th }}$ and $85^{\text {th }}$ percentile speeds continued to be consistent with the previous analyses. No non-overlapping intervals were observed for either percentile. Table 6 and Table 7 display the confidence intervals of $50^{\text {th }}$ and $85^{\text {th }}$ percentile speeds, respectively. From these tables it can be seen that the confidence intervals for the westbound SE Harrison west of $30^{\text {th }}$ dataset are quite similar when comparing the two vehicle configurations. The $50^{\text {th }}$ percentile confidence intervals in mph were $(22.09,23.55)$ and $(22.96,23.93)$; the $85^{\text {th }}$ percentile confidence intervals were $(25.30,26.70)$ and $(25.51,27.13)$. The largest discrepancy between confidence intervals for the $50^{\text {th }}$ percentile speeds was found with the eastbound SE Harrison west of $23^{\text {rd }}$ dataset. For the $85^{\text {th }}$ percentile speeds, the westbound SE Lincoln east of $48^{\text {th }}$ dataset produced the biggest difference. In both cases, the confidence intervals had a high degree of accordance and differences in bounds were less than two miles per hour $(3.2 \mathrm{~km} / \mathrm{h})$.

\section{Insert Table 6 HERE}

\section{Insert Table 7 HERE}

\section{DISCUSSION}

When considered in whole, the results of the $t$-tests and 95\% confidence intervals indicate that bicycles are not likely to lead to reduced passenger car travel speed, despite their differences in performance capabilities and the absence of bicycle lanes. In most cases, the differences in speed were not significant from a practical standpoint. However, this study did find a few instances where differences were seen.

For the analysis including all 24 hours, the most apparent exception occurred with the SE Harrison east of $27^{\text {th }}$ westbound dataset where the mean speeds between the two class two vehicle configurations were highly statistically different, i.e. the null hypothesis was rejected, with $p=6.0 \mathrm{E}-05$, and the $95 \%$ confidence intervals for the $50^{\text {th }}$ percentile speeds were non-overlapping. At this location, traffic travels downhill at a grade greater than $4 \%$ in the westbound direction which might encourage bicycles to travel at a higher speed, thereby lowering the desire of a motor vehicle to overtake immediately and instead be satisfied traveling temporarily at a slightly reduced speed. Additionally, it is possible that the presence of the all-way stop at $26^{\text {th }}$ influences passing behavior with motor vehicles preferring to delay overtaking a bicycle until after they clear the traffic control device. While the results of the analysis did find a statistically significant difference in speed at this location, the difference is relatively small - a $5.3 \%$ and $6.6 \%$ reduction, or $1.27 \mathrm{mph}(2.04 \mathrm{~km} / \mathrm{h})$ and $1.58 \mathrm{mph}(2.54 \mathrm{~km} / \mathrm{h})$ - for mean and $50^{\text {th }}$ percentile speeds, respectively. Moreover, the $95 \%$ confidence intervals for the $85^{\text {th }}$ percentile speeds do not illustrate a distinguishable difference. The peak hour analysis provided additional evidence that bicycles do not cause lower passenger car speeds at this location, as confirmed by the $t$-test results, which failed to reject the null hypothesis $(p=0.407)$.

The null hypothesis was rejected for both the eastbound and westbound directions at SE Harrison west of $30^{\text {th }}$ and the westbound direction at SE Lincoln east of $48^{\text {th }}$, showing statistically significant differences when the $t$-test was applied in the 24-hour analysis $(p=0.0026, p=0.047$, and $p=0.027$, respectively). Nevertheless, the $95 \%$ confidence intervals calculated for the $50^{\text {th }}$ and $85^{\text {th }}$ percentile speeds at these locations did not indicate a relevant difference in speed. The difference in mean speed at these sites was limited to roughly $0.5 \mathrm{mph}(0.8 \mathrm{~km} / \mathrm{h})$. For peak hours, only the westbound SE Harrison west of $30^{\text {th }}$ dataset produced a rejection of the null hypothesis, displaying a statistically significant difference in mean speeds equating to less than one mile per hour $(1.6 \mathrm{~km} / \mathrm{h})$. The all-way stop at $30^{\text {th }}$ and the double yellow line just west of it may discourage the passing behavior of eastbound traffic on Harrison in a similar manner as described above, leading to the nominal speed difference when all hours are 
considered. Westbound traffic at this location may also be influenced by the double yellow line, inhibiting passing behavior. The minor difference observed at the SE Lincoln location could be attributed to the higher occupancy rate of street parking, effectively decreasing the space available for motor vehicles to safely pass bicycles. It bears reiterating that apart from one dataset, we fail to reject the null hypothesis as no significant differences in speeds were found for peak hour traffic.

The $t$-test for the SE Hawthorne east of $44^{\text {th }}$ dataset did reject the null hypothesis $(p=0.015)$, and a difference in mean speeds of approximately $3 \mathrm{mph}(4.8 \mathrm{~km} / \mathrm{h})$ was observed between scenarios (i) and (ii). Similar differences were seen for the $50^{\text {th }}$ and $85^{\text {th }}$ percentile speeds at this location, although the confidence intervals were found to overlap. SE Hawthorne carries a district collector classification whereas all other locations are lower classed local streets. Traffic volume along SE Hawthorne is well in excess of even the most generous design guidelines for shared roads and motor vehicle operating speeds are above the recommended target of $20-25 \mathrm{mph}(32-40 \mathrm{~km} / \mathrm{h})$. Combined with the high occupancy of street parking which removes effective width for passing, these characteristics likely contributed to the small differences observed between scenarios (i) and (ii).

On Harrison and Lincoln, the road width, low to moderate parking occupancy, and lack of a center lane delineator likely all contribute to the ability of passenger cars to maintain their speed. The low traffic volume provides adequate opportunity for passing, and the speed limit of $25 \mathrm{mph}(40 \mathrm{~km} / \mathrm{h})$ helps to mitigate the amount a motor vehicle needs to slow down when approaching or overtaking a bicycle. Although minor differences in speeds were found at a few locations where sharrows were present, the magnitude of the difference was smaller than at the SE Hawthorne location where sharrows are absent. It is likely that the higher speed difference and higher levels of motorized traffic (see Table 1) make SE Hawthorne a more streesful roadway for cyclists [21] and this in turn contributes to explain the lower bicycle volumes on SE Hawthorne.

Finally, although concerns have been voiced that increased bicycle volume on shared roads could lead to significantly reduced motor vehicle speeds, the results of this study failed to show a positive correlation between the magnitude of difference in mean speeds between the two scenarios and the percent of traffic comprised of class one vehicles.

\section{CONCLUSIONS}

Speed distributions, the mean, and the $50^{\text {th }}$ and $85^{\text {th }}$ percentile speeds for two scenarios were examined: (i) a passenger car that was preceded by a bicycle and (ii) a passenger car that was preceded by another passenger car. Peak hour traffic and 24-hour traffic speeds were analyzed.

This paper has presented evidence from urban roads without bicycle lanes in Portland, indicating that bicycles do not reduce passenger car speeds by more than one mile per hour $(1.6 \mathrm{~km} / \mathrm{h})$ at most locations. This finding was reinforced by the results of the $95 \%$ confidence intervals for the $50^{\text {th }}$ and $85^{\text {th }}$ percentile speeds and the separate analysis performed for peak hours. While the results of the analysis did find five of the eleven datasets to have statistically significant differences in mean speed, rejecting the null hypothesis when all hours were analyzed, this result is in part due to a large number of observations since the actual speed differences are trivial in a practical sense. Higher speed differences, in the order of two to three miles per hour (3.2-4.8 km/h), were found only at locations that do not meet the guidelines for a shared road.

Due to the limited variability in roadway characteristics of the sites analyzed, the conclusions drawn may not be directly transferable to all roadways without bicycle lanes. Nonetheless, the results presented here deliver encouragement for incorporating shared roads into urban bicycle networks to support an increasing bicycle mode share without negatively impacting travel speed or creating congestion, provided that cities ensure these shared roads follow recommended bikeway guidelines.

Future work should include roadways with a wider variety of vehicle classifications and roadway characteristics such as ADT, grade, and pavement markings to evaluate the consistency of the findings presented here and to further investigate the effects the roadway environment and traffic composition may have on vehicle-bicycle interactions and resulting travel speed. 


\section{ACKNOWLEDGMENTS}

2 The authors would like to acknowledge Tom Jensen and Scott Batson of PBOT for providing the data 3 used in this analysis.

4

5 AUTHOR CONTRIBUTIONS

6 The authors confirm contribution to the paper as follows: study conception and design: MAF, AU; data 7 collection: PBOT; analysis and interpretation of results: JSS, MAF, AU; draft manuscript preparation:

8 JSS, MAF, AU. All authors reviewed the results and approved the final version of the manuscript. 
Schaefer, Figliozzi, and Unnikrishnan

1 TABLE 1 Characteristics of the Data Collection Sites

\begin{tabular}{|c|c|c|c|c|c|c|c|}
\hline \multirow[b]{2}{*}{ Location } & \multirow[b]{2}{*}{ Road Markings } & \multirow{2}{*}{$\begin{array}{l}\text { Grade } \\
\%\end{array}$} & \multirow{2}{*}{$\begin{array}{l}\text { Road Width } \\
\text { (ft.) }\end{array}$} & \multicolumn{2}{|l|}{ ADT } & \multicolumn{2}{|c|}{ \% Class 1} \\
\hline & & & & EB & WB & EB & WB \\
\hline SE Harrison $\mathrm{W}$ of $23^{\text {rd }}$ & Sharrow & 4.1 & 35.5 & 663 & 1084 & 67 & 46 \\
\hline SE Harrison $\mathrm{W}$ of $26^{\text {th }}$ & Sharrow* & 4.0 & 35.5 & 553 & 923 & 22 & 34 \\
\hline SE Harrison E of $27^{\text {th }}$ & Sharrow & 4.3 & 35.5 & 1249 & 1462 & 17 & 24 \\
\hline SE Harrison W of $30^{\text {th }}$ & Sharrow* & 1.6 & 35.5 & 1594 & 1450 & 31 & 34 \\
\hline SE Lincoln E of $48^{\text {th }}$ & Sharrow & 1.4 & 34 & 642 & 719 & 6 & 13 \\
\hline SE Hawthorne E of $44^{\text {th }}$ & $\begin{array}{l}\text { Center left-hand } \\
\text { turn lane }\end{array}$ & 0 & $\begin{array}{l}51 \text { with } 12 \mathrm{ft} \text {. } \\
\text { center lane }\end{array}$ & na & 6568 & na & 2 \\
\hline
\end{tabular}

Note: $E B=$ eastbound, $W B=$ westbound, $n a=$ not applicable.

*Double yellow lines at these sites are only placed within $40 \mathrm{ft}$. of a traffic control device.

TABLE $2 t$-Test between Mean Speeds

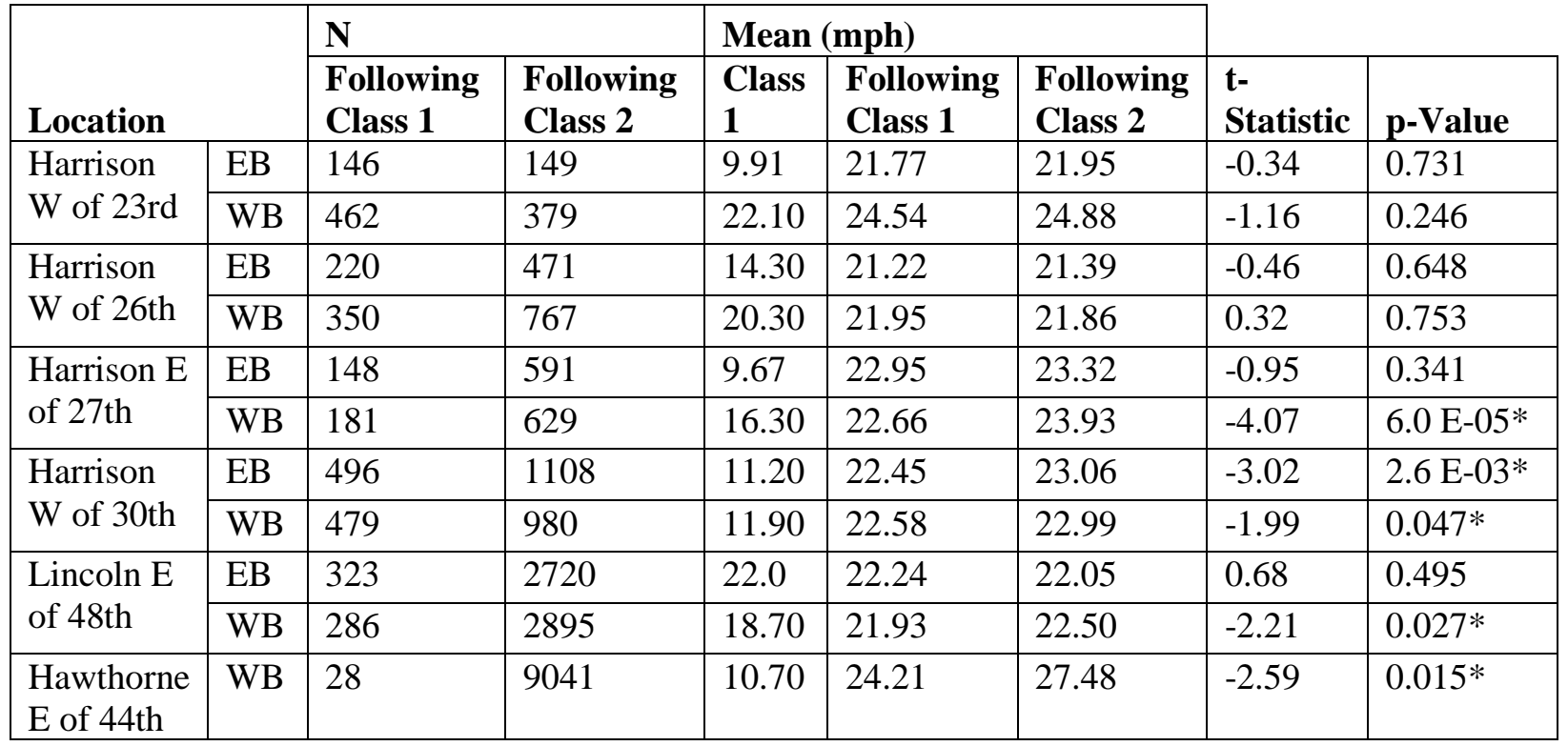

6 Note: $\mathrm{N}=$ number of observations.

$7 \quad *>95 \%$ significance. 
Schaefer, Figliozzi, and Unnikrishnan

1 TABLE $35^{\text {th }}$ Percentile Speeds and 95\% Confidence Intervals (in mph)

\begin{tabular}{|c|c|c|c|c|c|}
\hline \multirow{2}{*}{\multicolumn{2}{|c|}{ Location }} & \multicolumn{2}{|c|}{ Following Class 1} & \multicolumn{2}{|c|}{ Following Class2 } \\
\hline & & \multirow{2}{*}{$\begin{array}{l}\mathbf{5 0}^{\text {th }} \text { Percentile } \\
21.72\end{array}$} & \multirow{2}{*}{$\begin{array}{l}\text { CI } \\
(20.79,22.61)\end{array}$} & \multirow{2}{*}{$\begin{array}{l}\mathbf{5 0}^{\text {th }} \text { Percentile } \\
21.53\end{array}$} & \multirow{2}{*}{$\frac{\text { CI }}{(21.08,22.49)}$} \\
\hline SE Harrison $\mathrm{W}$ of $23^{\text {rd }}$ & $\mathrm{EB}$ & & & & \\
\hline & WB & 24.56 & $(23.91,25.09)$ & 24.93 & $(24.55,25.57)$ \\
\hline \multirow[t]{2}{*}{ SE Harrison $\mathrm{W}$ of $26^{\text {th }}$} & EB & 21.79 & $(21.05,22.46)$ & 21.85 & $(21.26,22.26)$ \\
\hline & WB & 22.68 & $(21.96,23.08)$ & 22.36 & $(22.10,22.63)$ \\
\hline \multirow[t]{2}{*}{ SE Harrison E of $27^{\text {th }}$} & EB & 23.10 & $(22.10,24.07)$ & 23.50 & $(22.90,23.78)$ \\
\hline & WB & 22.44 & $(22.17,23.07)^{*}$ & 24.02 & $(23.80,24.33)^{*}$ \\
\hline \multirow[t]{2}{*}{ SE Harrison W of $30^{\text {th }}$} & EB & 22.90 & $(22.53,23.38)$ & 23.27 & $(23.08,23.57)$ \\
\hline & WB & 22.76 & $(22.49,23.21)$ & 23.24 & $(22.99,23.46)$ \\
\hline \multirow[t]{2}{*}{ SE Lincoln $\mathrm{E}$ of $48^{\text {th }}$} & EB & 22.50 & $(21.93,23.43)$ & 22.30 & $(22.10,22.50)$ \\
\hline & WB & 21.88 & $(21.21,22.66)$ & 22.71 & $(22.57,22.90)$ \\
\hline SE Hawthorne E of $44^{\text {th }}$ & WB & 24.84 & $(21.98,28.45)$ & 28.06 & $(27.93,28.16)$ \\
\hline
\end{tabular}

Note: $\mathrm{CI}=$ confidence interval.

* Non-overlapping confidence intervals.

5 TABLE $485^{\text {th }}$ Percentile Speeds and 95\% Confidence Intervals (in mph)

\begin{tabular}{|c|c|c|c|c|c|}
\hline \multirow{2}{*}{\multicolumn{2}{|c|}{ Location }} & \multicolumn{2}{|c|}{ Following Class 1} & \multicolumn{2}{|c|}{ Following Class2 } \\
\hline & & $85^{\text {th }}$ Percentile & CI & $85^{\text {th }}$ Percentile & CI \\
\hline \multirow[t]{2}{*}{ SE Harrison $\mathrm{W}$ of $23^{\text {rd }}$} & EB & 27.25 & $(26.05,28.72)$ & 25.96 & $(25.25,27.94)$ \\
\hline & WB & 29.03 & $(28.48,29.41)$ & 29.07 & $(28.62,29.82)$ \\
\hline \multirow[t]{2}{*}{ SE Harrison $\mathrm{W}$ of $26^{\text {th }}$} & EB & 25.98 & $(25.32,26.68)$ & 25.60 & $(25.07,26.09)$ \\
\hline & WB & 26.39 & $(25.99,27.10)$ & 26.13 & $(25.54,26.49)$ \\
\hline \multirow[t]{2}{*}{ SE Harrison E of $27^{\text {th }}$} & EB & 27.44 & $(26.60,28.14)$ & 27.43 & $(27.00,28.07)$ \\
\hline & WB & 26.41 & $(25.95,27.94)$ & 27.27 & $(26.88,27.74)$ \\
\hline \multirow[t]{2}{*}{ SE Harrison $\mathrm{W}$ of $30^{\text {th }}$} & EB & 26.00 & $(25.59,26.50)$ & 26.26 & $(26.03,26.63)$ \\
\hline & WB & 26.07 & $(25.58,26.43)$ & 26.04 & $(25.78,26.44)$ \\
\hline \multirow[t]{2}{*}{ SE Lincoln E of $48^{\text {th }}$} & EB & 26.93 & $(26.28,27.57)$ & 26.27 & $(26.11,26.50)$ \\
\hline & WB & 26.24 & $(25.36,27.15)$ & 26.46 & $(26.29,26.61)$ \\
\hline SE Hawthorne E of $44^{\text {th }}$ & WB & 30.60 & $(29.34,35.50)$ & 32.69 & $(32.53,32.82)$ \\
\hline
\end{tabular}

6

7

TABLE 5 -Test between Mean Speeds for Peak Hours

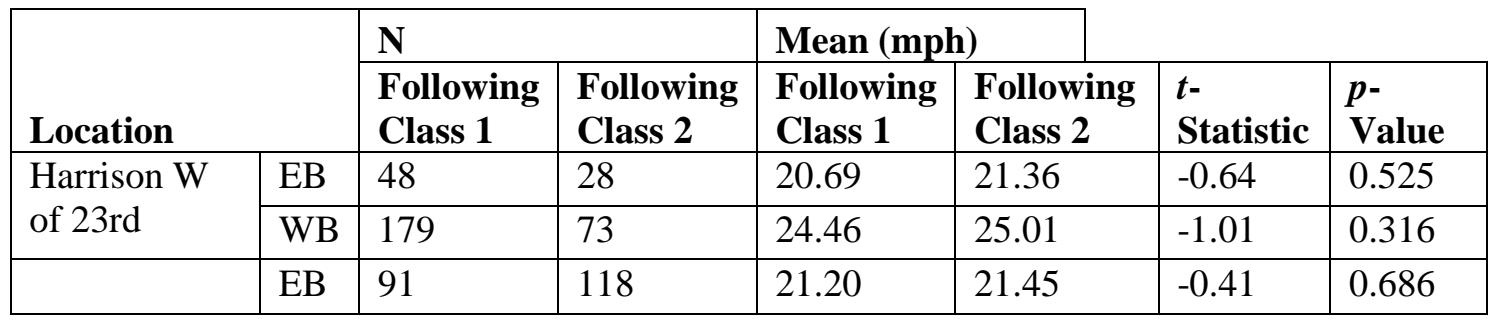


Schaefer, Figliozzi, and Unnikrishnan

\begin{tabular}{|l|l|l|l|l|l|l|l|}
\hline $\begin{array}{l}\text { Harrison W } \\
\text { of 26th }\end{array}$ & WB & 131 & 195 & 22.06 & 22.17 & -0.21 & 0.835 \\
\hline $\begin{array}{l}\text { Harrison E of } \\
\text { 27th }\end{array}$ & EB & 79 & 181 & 23.01 & 23.49 & -0.89 & 0.377 \\
\cline { 2 - 8 } & WB & 92 & 199 & 23.16 & 23.56 & -0.83 & 0.407 \\
\hline $\begin{array}{l}\text { Harrison W } \\
\text { of 30th }\end{array}$ & EB & 203 & 262 & 22.15 & 22.88 & -1.95 & 0.051 \\
\cline { 2 - 8 } & WB & 169 & 229 & 22.42 & 23.21 & -2.13 & $0.034^{*}$ \\
\hline \multirow{2}{*}{$\begin{array}{l}\text { 4incoln E of } \\
\text { 48th }\end{array}$} & EB & 102 & 897 & 21.90 & 22.10 & -0.40 & 0.687 \\
\cline { 2 - 8 } & WB & 77 & 937 & 21.49 & 22.18 & -1.40 & 0.164 \\
\hline
\end{tabular}

1

2

TABLE $650^{\text {th }}$ Percentile Speeds and 95\% Confidence Intervals for Peak Hours (in mph)

\begin{tabular}{|l|l|l|l|l|l|}
\hline \multirow{2}{*}{ Location } & \multicolumn{2}{l|}{ Following Class 1 } & \multicolumn{2}{l|}{ Following Class2 } \\
\cline { 3 - 6 } & $\mathbf{5 0}^{\text {th }}$ Percentile & CI & $\mathbf{5 0}^{\text {th }}$ Percentile & CI \\
\hline SE Harrison W of $23^{\text {rd }}$ & EB & 20.63 & $(19.93,22.16)$ & 20.59 & $(19.73,24.10)$ \\
\cline { 2 - 6 } & WB & 24.40 & $(23.56,25.36)$ & 25.00 & $(24.26,26.25)$ \\
\hline \multirow{3}{*}{ SE Harrison W of $2^{\text {th }}$} & EB & 22.05 & $(20.28,22.77)$ & 22.10 & $(20.98,22.76)$ \\
\cline { 2 - 6 } & WB & 22.96 & $(21.63,23.92)$ & 23.17 & $(22.16,23.72)$ \\
\hline SE Harrison E of $27^{\text {th }}$ & EB & 23.18 & $(22.12,24.40)$ & 23.40 & $(22.93,24.23)$ \\
\cline { 2 - 6 } & WB & 23.41 & $(22.05,24.27)$ & 23.84 & $(23.40,24.21)$ \\
\hline SE Harrison W of $30^{\text {th }}$ & EB & 22.78 & $(22.18,23.46)$ & 23.31 & $(22.67,23.78)$ \\
\cline { 2 - 6 } & WB & 22.62 & $(22.09,23.55)$ & 23.47 & $(22.96,23.93)$ \\
\hline SE Lincoln E of 48 & EB & 22.47 & $(21.61,23.67)$ & 22.37 & $(22.10,22.71)$ \\
\cline { 2 - 6 } & WB & 21.11 & $(20.04,22.63)$ & 22.35 & $(22.01,22.69)$ \\
\hline
\end{tabular}

4

\begin{tabular}{|c|c|c|c|c|c|}
\hline \multirow{2}{*}{\multicolumn{2}{|c|}{ Location }} & \multicolumn{2}{|c|}{ Following Class 1} & \multicolumn{2}{|c|}{ Following Class2 } \\
\hline & & \multirow{2}{*}{$\frac{8^{\text {th }} \text { Percentile }}{25.58}$} & \multirow{2}{*}{$\begin{array}{l}\text { CI } \\
(23.31,27.89)\end{array}$} & \multirow{2}{*}{$\begin{array}{l}\text { 85 }^{\text {th }} \text { Percentile } \\
26.47\end{array}$} & \multirow{2}{*}{$\begin{array}{l}\text { CI } \\
(24.29,28.30)\end{array}$} \\
\hline SE Harrison $\mathrm{W}$ of $23^{\text {rd }}$ & EB & & & & \\
\hline & WB & 29.21 & $(28.50,30.00)$ & 28.88 & $(28.18,30.23)$ \\
\hline \multirow[t]{2}{*}{ SE Harrison $\mathrm{W}$ of $26^{\text {th }}$} & EB & 25.64 & $(24.45,26.83)$ & 25.68 & $(25.01,26.92)$ \\
\hline & WB & 26.88 & $(25.97,28.09)$ & 26.87 & $(26.32,27.26)$ \\
\hline \multirow[t]{2}{*}{ SE Harrison E of $27^{\text {th }}$} & EB & 26.82 & $(26.17,28.98)$ & 27.91 & $(26.74,28.74)$ \\
\hline & WB & 27.31 & $(26.30,28.32)$ & 26.54 & $(26.07,27.39)$ \\
\hline \multirow[t]{2}{*}{ SE Harrison $\mathrm{W}$ of $30^{\text {th }}$} & EB & 25.86 & $(25.19,26.52)$ & 26.30 & $(25.92,27.09)$ \\
\hline & WB & 25.97 & $(25.30,26.70)$ & 26.25 & $(25.51,27.13)$ \\
\hline \multirow[t]{2}{*}{ SE Lincoln E of $48^{\text {th }}$} & EB & 26.53 & $(25.61,27.93)$ & 26.32 & $(26.00,26.89)$ \\
\hline & WB & 25.95 & $(24.45,27.62)$ & 26.32 & $(25.87,26.67)$ \\
\hline
\end{tabular}

TABLE $78^{\text {th }}$ Percentile Speeds and 95\% Confidence Intervals for Peak Hours (in mph) 


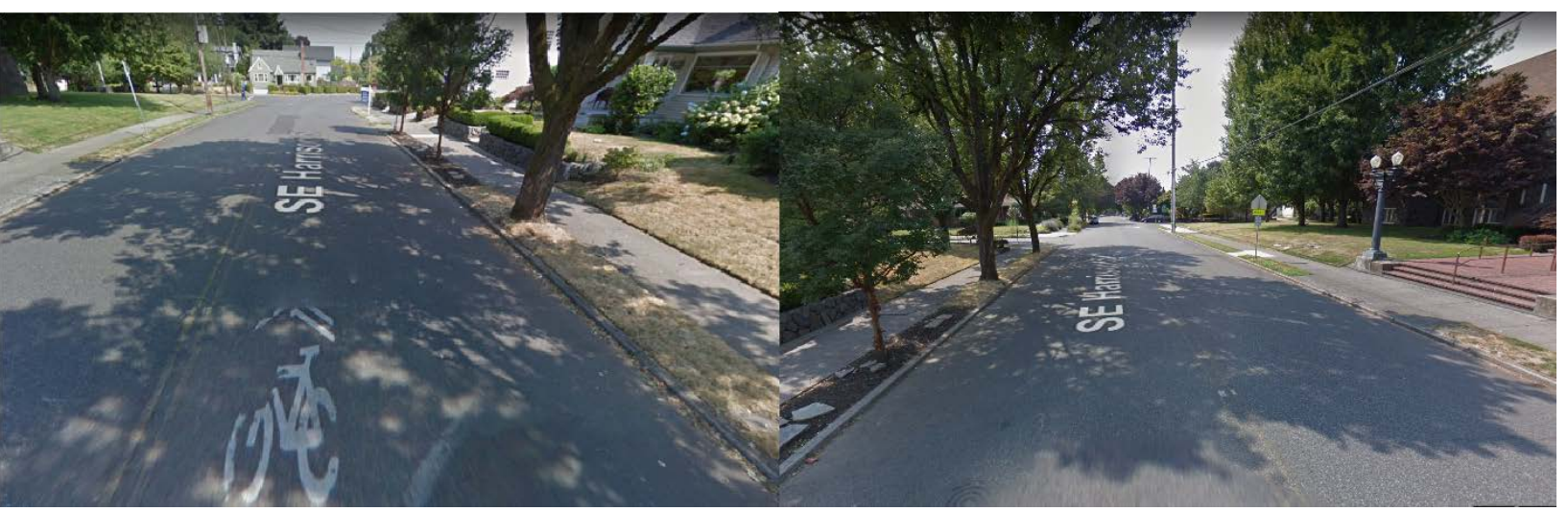

Figure 1 SE Harrison west of $30^{\text {th }}$, looking east (left) and west (right).[17]

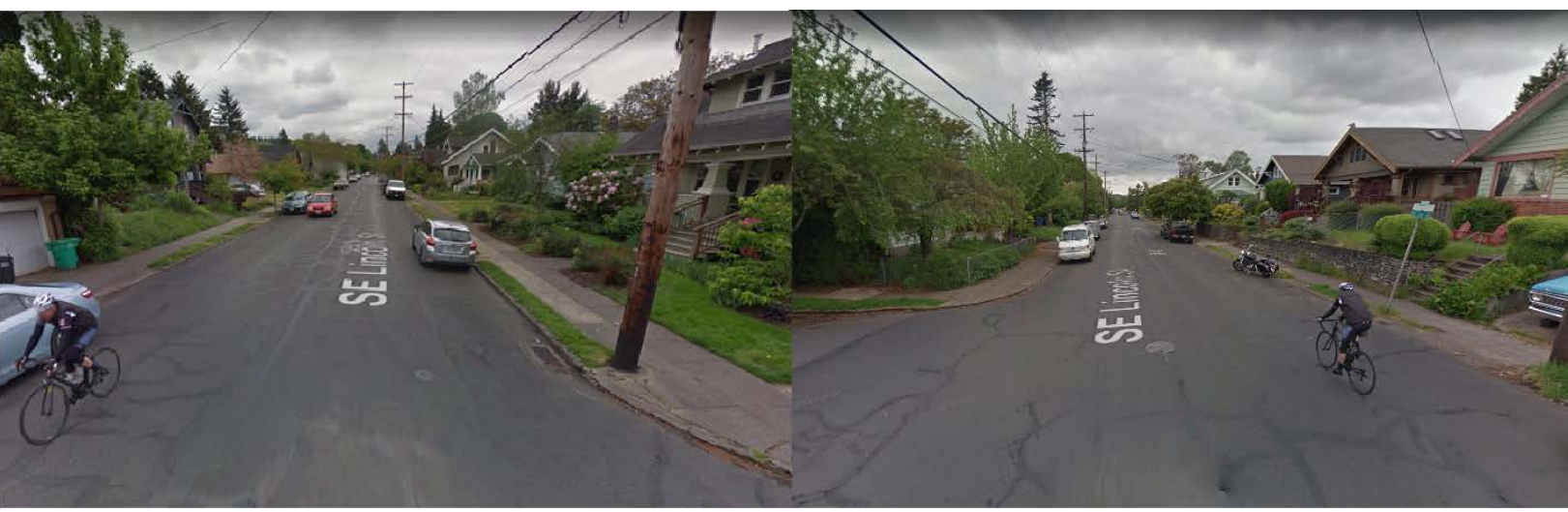

Figure 2 SE Lincoln east of $48^{\text {th }}$, looking east (left) and west (right).[18]

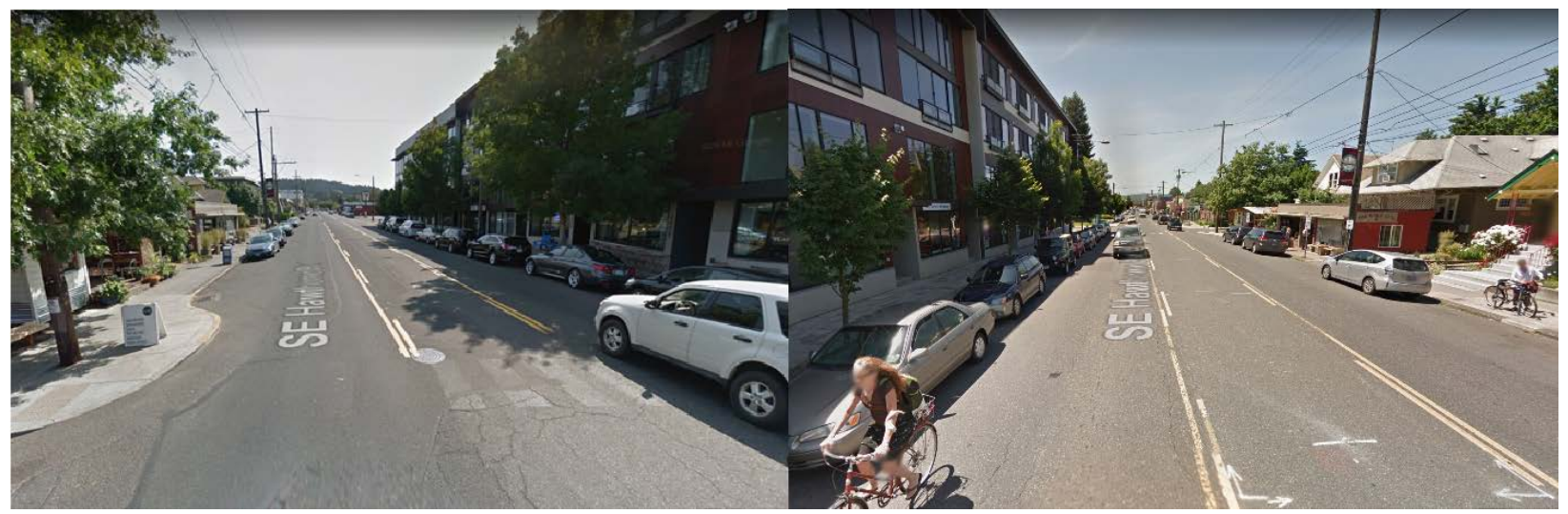

Figure 3 SE Hawthorne east of $44^{\text {th }}$, looking east (left) and west (right).[19] 

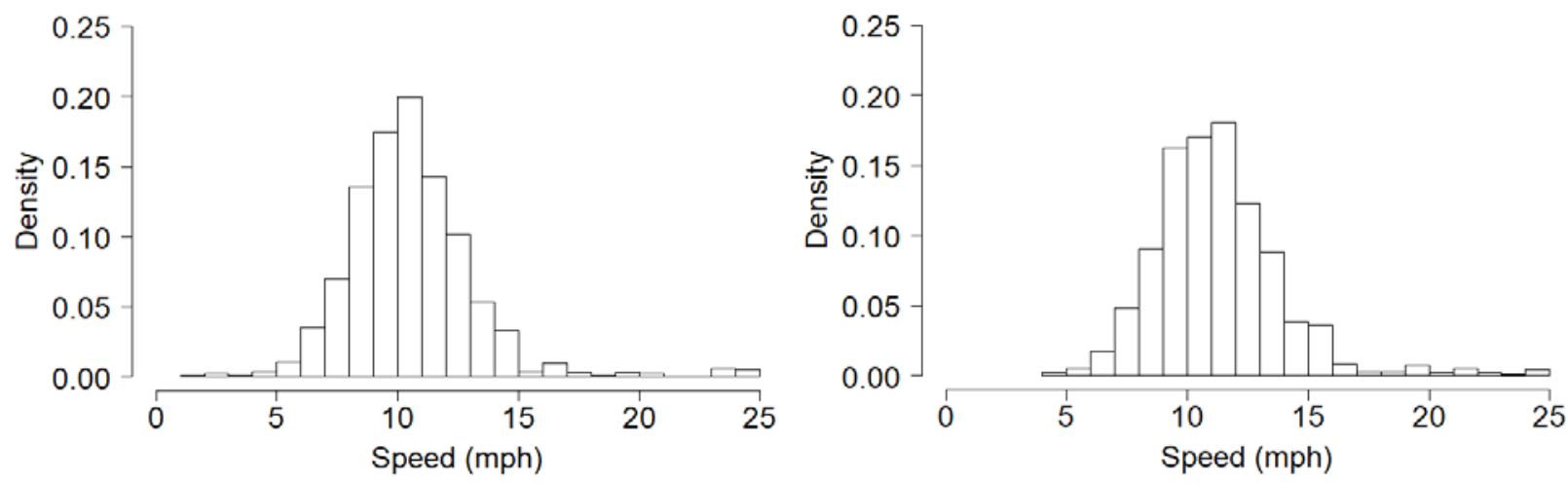

Figure 4 Class one speed distributions for the SE Harrison west of $30^{\text {th }}$ location eastbound (right) and westbound (left).
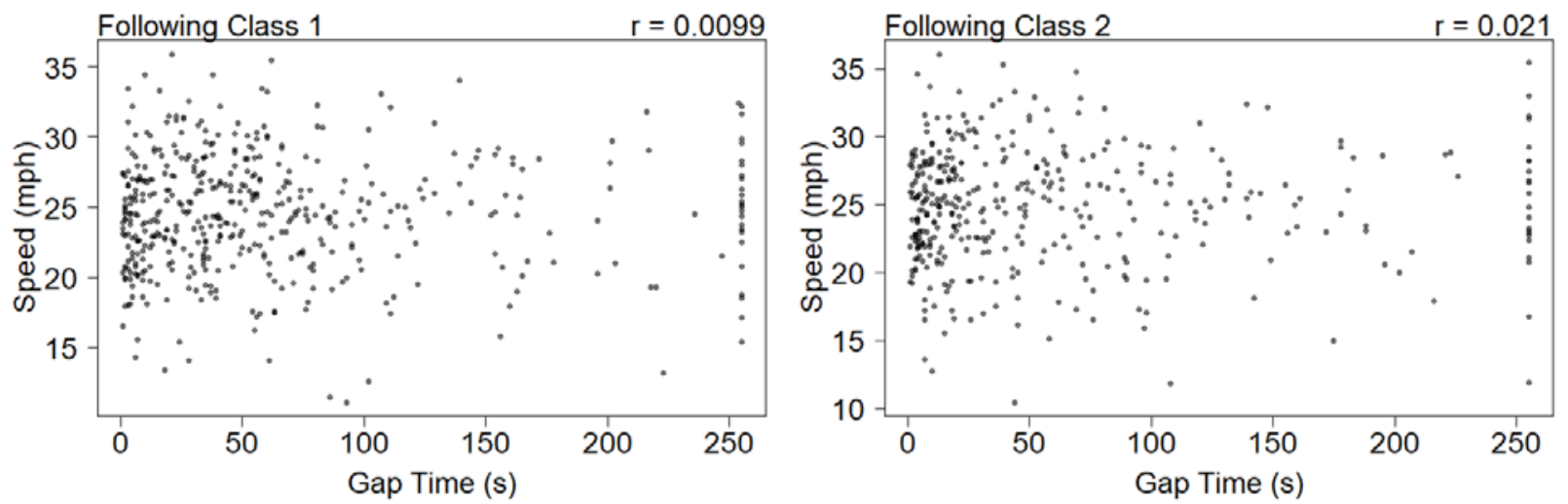

Figure 5 Gap analysis plots for SE Harrison west of $23^{\text {rd }}$, westbound. Class two following class one configuration (left) and class two following class two configuration (right). 
1
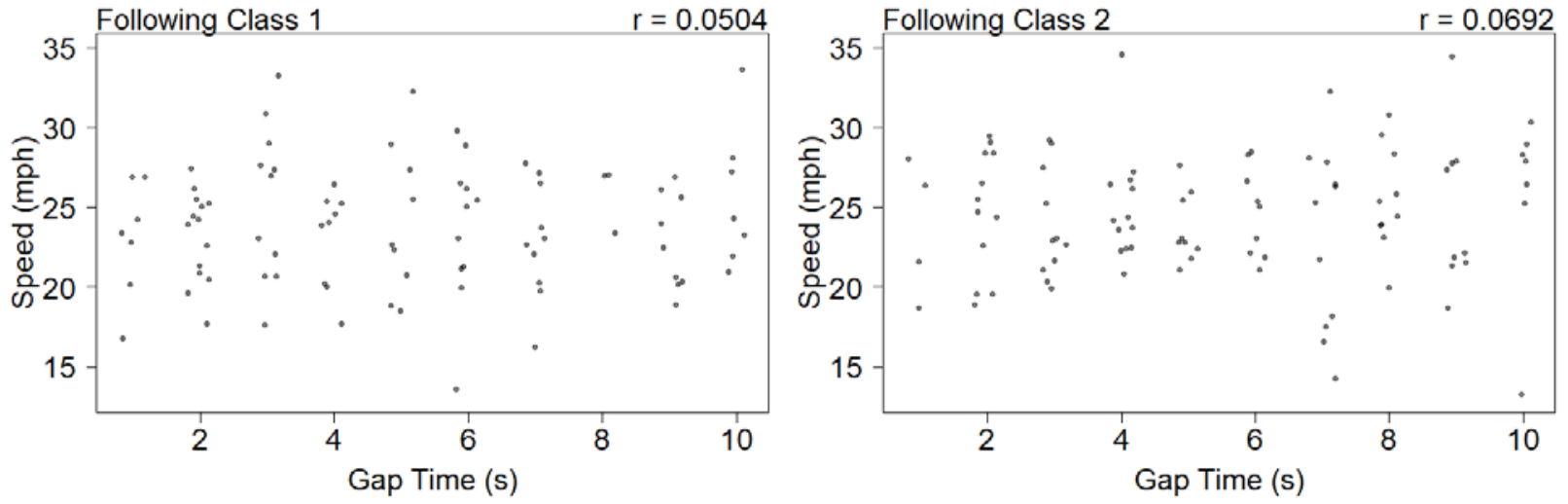

Figure 6 Gap analysis plots for SE Harrison west of $23^{\text {rd }}$, westbound limited to observations of a 10 s gap time. Class two following class one configuration (left) and class two following class two configuration (right). Notice the similar data trend as when all observations are retained.
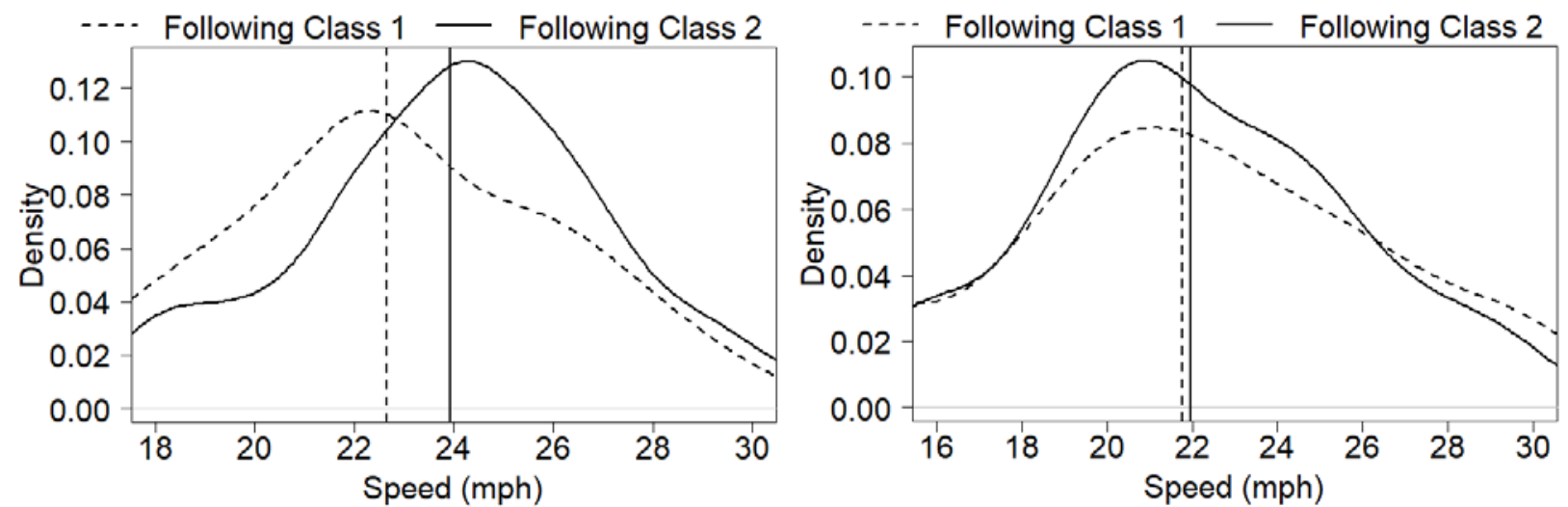

Figure 7 Empirical distributions with mean speeds for westbound SE Harrison east of $27^{\text {th }}$ (left) and eastbound SE Harrison west of $23^{\text {rd }}$ (right). 

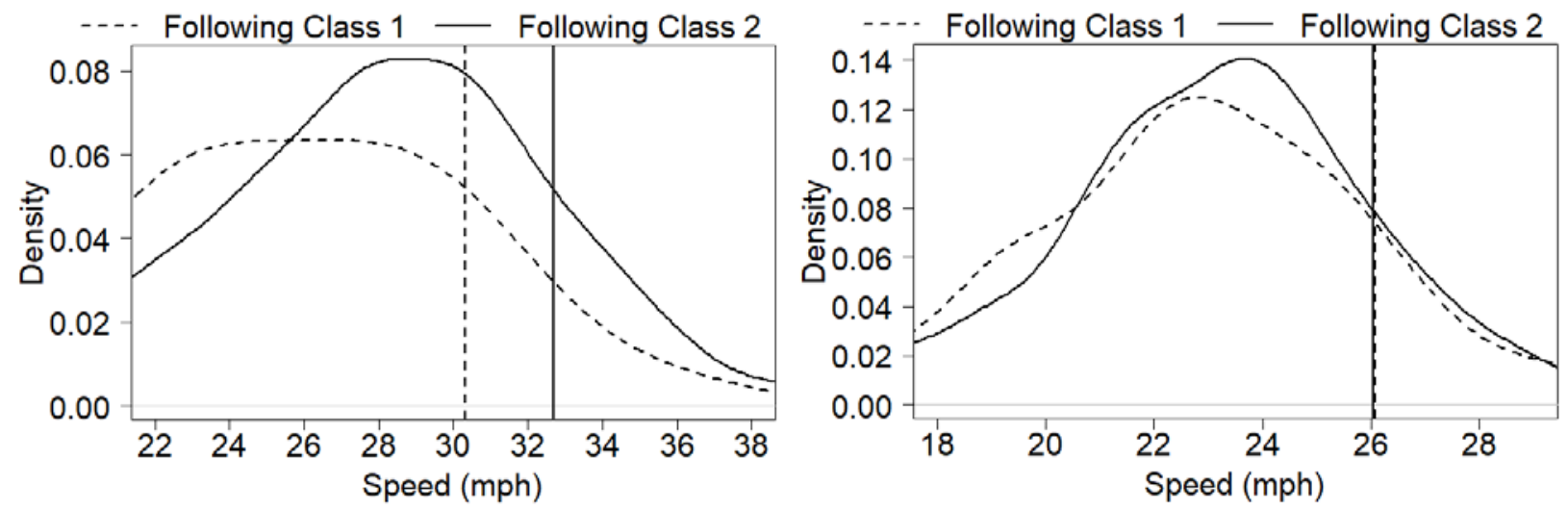

1

3

4

5

6

7

Figure 8 Empirical distributions with the $85^{\text {th }}$ percentile speeds for westbound SE Hawthorne east of $44^{\text {th }}$ (left) and westbound SE Harrison west of $30^{\text {th }}$ (right). 


\section{REFERENCES}

1. United States Census Bureau. American FactFinder - COMMUTING CHARACTERISTICS BY SEX, 2017 American Community Survey 1-Year Estimates [Internet]. Washington DC: US Census Bureau; 2017 [cited 2019 Jul 25]. Available from: https://factfinder.census.gov/faces/tableservices/jsf/pages/productview.xhtml?pid=ACS_17_1YR _S0801\&prodType=table

2. City of Portland Oregon. Bicycles in Portland Fact Sheet [Internet]. Portland, OR: City of Portland; 2019 [updated 2019 Apr; cited 2019 Jul 25]. Available from: https://www.portlandoregon.gov/transportation/article/407660

3. City of Portland Oregon. Portland Bicycle Plan for 2030 [pdf] [Internet]. Portland, OR: City of Portland; 2010 Feb 11 [cited 2019 Jul 25]. Available from: https://www.portlandoregon.gov/transportation/article/289122

4. Andersen T, Bredal F, Weinreich M, Jensen N, Riisgaard-Dam M, Nielsen MK. Collection of cycle concepts 2012. $2^{\text {nd }}$ ed. Denmark: Cycling Embassy of Denmark, 2012. Planning the cycling infrastructure; p. 53-54.

5. Andersen, M. Real Talk: Bikes don’t reduce congestion without bike lanes [Internet]. Boulder, CO: PeopleForBikes; 2015 Apr 22 [cited 2019 Jul 25]. Available from: https://peopleforbikes.org/blog/real-talk-bikes-cant-reduce-congestion-without-bike-lanes/.

6. Gosse C, Clarens A. Quantifying the total cost of infrastructure to enable environmentally preferable decisions: the case of urban roadway design. Environ Res Lett. 2013 Mar;8(1):1-9.

7. Turner S, Sandt L, Toole J, Benz R, Patten R. FHWA university course on bicycle and pedestrian transportation: student workbook. McLean, VA: Texas Transportation Institute; 2006 Jul. Report No.: FHWA-HRT-05-133. p. 231-232.

8. Schultheiss B, Goodman D, Blackburn L, Wood A, Reed D, Elbech M. Bikeway selection guide. United States: Federal Highway Administration Office of Safety; 2019 Feb 1. Report No.: FHWA-SA-18-077. Washington DC: FHWA, p. 23.

9. National Association of City Transportation Officials. Urban bikeway design guide. $2^{\text {nd }}$ ed. Washington DC: Island Press; 2014 Mar 24.

10. Jia S, Peng H, Guo J, Chen H. Quantitative analysis of impact of bicycles on vehicles in urban mixed traffic. Journal of Transportation Systems Engineering and Information Technology. 2008 Apr 1;8(2):58-63.

11. Pein WE, Hunter WW, Stewart JR. Evaluation of the shared-use arrow. Tallahassee, FL: Florida Department of Transportation; 1999 Dec.

12. Brady J, Loskorn J, Mills A, Duthie J, Machemehl R. Effects of shared lane markings on bicyclist and motorist behavior along multi-lane facilities. Austin, TX: Center for Transportation Research, U. of Texas at Austin; 2010 Jul.

13. LaMondia J, Duthie J. Analysis of factors influencing bicycle-vehicle interactions on urban roadways by ordered probit regression. Transp Res Rec. 2012;2314(1):81-88.

14. Okech TC. Modeled performance characteristics of heterogeneous traffic streams containing nonmotorized vehicles. Transportation Research Board 82 ${ }^{\text {nd }}$ Annual Meeting [CD-ROM]. 2003

15. Federal Highway Administration. Traffic monitoring guide. Washington DC: US Department of Transportation; 2016. p. C-1.

16. Nordback K, Kothuri S, Phillips T, Gorecki C, Figliozzi, M. Accuracy of bicycle counting with pneumatic tubes in Oregon. Transp Res Rec. 2016;2593(1):8-17.

17. Google Maps. Google Street View, 2934 SE Harrison St. [Image on internet]. United States: Google; 2017 Aug [cited 2019 Jul 25]. Available from: https://goo.gl/maps/pVE3AsTUu1ZUhDoh6

18. Google Maps. Google Street View, 4749 SE Lincoln St. [Image on internet]. United States: Google; 2016 Apr [cited 2019 Jul 25]. Available from: https://goo.gl/maps/NxH3nCjBT3C4uwEG7 
19. Google Maps. Google Street View, 4380 SE Hawthorne Blvd. [Image on internet]. United States: Google; 2018 Aug [cited 2019 Jul 25]. Available from: https://goo.gl/maps/UeFUXGzze7DyuGeG7

20. Hallenbeck M, Rice M, Smith BL, Cornell-Martinez C, Wilkinson J. Vehicle volume distributions by classification. 1997 Jul. p. 29.

21. Blanc B, Figliozzi M. Modeling the impacts of facility type, trip characteristics, and trip stressors on cyclists’ comfort levels utilizing crowdsourced data. Transportation Research Record. 2016;2587(1):100-8. 